UCRL- JC- 107357

PREPRINT

\title{
Energy Production Using Fission Fragment Rockets
}

\author{
George Chapline \\ and \\ Yoshiyuki Matsuda
}

Lawrence Livermore National Laboratory

This Paper was Prepared for Submittal to:

Proceedings of the ICENES ' 91 Conference

on Emerging Nuclear Energy Systems

Monterey, California

June 16-21, 1991

August 1991

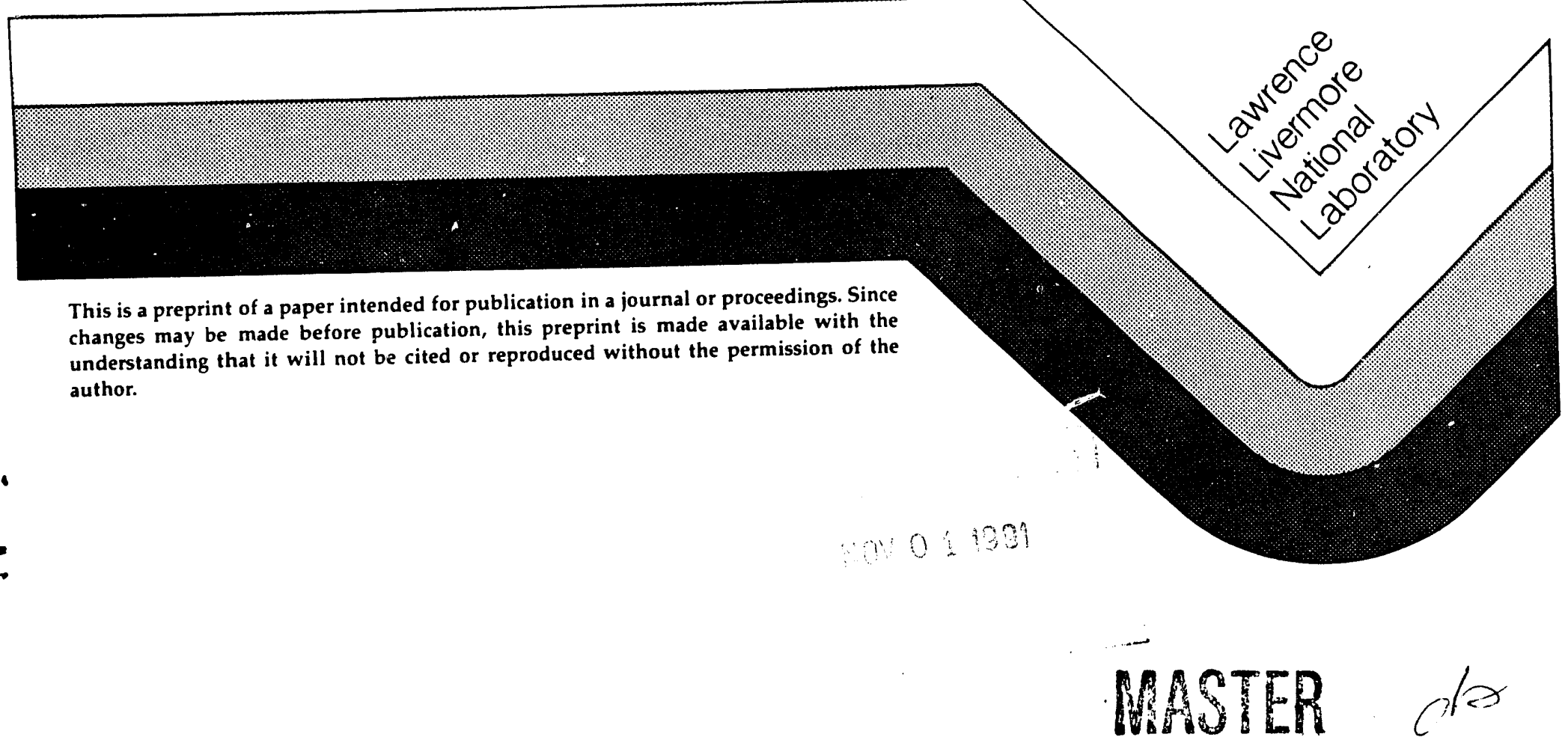




\section{DISCI.AIMER}

This document was prepared as an account of work sponsored by an agency of the United States Government. Neither the United States Government nor the University of California nor any of their employees, makes any warranty, express or implied, or assumes any legal liability or responsibility for the accuracy, completeness, or usefulness of any information, apparatus, product, or process disclosed, or represents that its use would not infringe privately owned rights. Reference herein to any specific commercial products, process, or service by trade name, trademark, manufacturer, or otherwise, does not necessarily constitute or imply its endorsement, recommendation, or favoring by the United States Government or the University of California. The views and opinions of authors expressed herein do not necessarily state or reflect those of the United States Government or the University of California, and shall not be used for advertising or product endorsement purposes. 


\author{
George Chapline and Yoshiyuki Matsuda \\ Lawrence Livermore National Laboratory \\ Physics Department \\ P.O. Box 808, L-297 \\ Livermore, CA 94550 \\ $415-422-4106$
}

UCRL-JC--107357

DE92 002192

\begin{abstract}
Fission fragment rockets are nuclear reactors with a core consisting of thin fibers in a vacuum, and which use magnetic fields to extract the fission fragments from the reactor core. As an altemative to ordinary nuclear reactors, fission fragment rockets would have the advantages:
\end{abstract}

1. Approximately twice as efficient if one can directly convert the fission fragment energy into electricity;

2. By reducing the buildup of a fission fragment inventory in the reactor one could avoid a Chernobyl type disaster;

3. Collecting the fission fragments outside the reactor could simplify the waste disposal problem.

\section{INTRODUCTION}

A fission fragment rocket is a nuclear reactor which operates in a vacuum and where the fission fragments are continuously extracted from the reactor core using magnetic fields. ${ }^{1,2,3}$ In our conception of the fission fragment rocket the fuel elements consist of thin ( $\$ 3 \mu \mathrm{m}$ diameter) carbon fibers coated with a few thousand Angstroms of fissile material. This allows the fission fragments to escape from the fissile fuel with a high probability. ${ }^{2}$ Although the fission fragment rocket idea has been mainly developed ${ }^{3}$ as a means for achieving very high specific impulse in a spacecraft propulsion system, the fission fragment rocket concept may also be of interest in connection with the more mundane problem of electric power Production here on earth. In fact, for a number of reasons electric power production is almost certainly a more practical application than spacecraft propulsion. For example, spacecraft propulsion puts a premium on the weight of the spacecraft. In the case of fission fragment propulsion this means that $A m^{242 m}$ is by far the most desirable fuel because of its extraordinarily iarge thermal fission cross section. A more practical fuel such as $\mathrm{Pu}^{239}$ or $\mathrm{U}^{235}$ would require using a much heavier moderator/ reflector. On the other hand, an earthbound fission fragment rocket using plutonium or uranium as the fuel offers the tantalizing possibility of allowing one to convert fission fragment kinetic energy directly into high voltage electricity. ${ }^{4}$ Indeed pursuit of this possibility could lead to nuclear power plants that are both safer and significantly more efficient than present day commercial nuclear reactors.

\section{NEUTRONICANALSIS}

In order for the fission fragments to have a reasonable range the mean density of material inside the reactor core must be fairly low. For example, the range of fission fragments in air at normal pressure and temperature is about $2 \mathrm{~cm}$. This means that a layer of fuel element fibers cannot be thicker than about $.002 \mathrm{gm} / \mathrm{cm}^{2}$, or else the fission fragments won't escape from the layer. If the reactor core contains a stack of fuel layers, each $.002 \mathrm{gm} / \mathrm{cm}^{2}$ thick and separated by $20 \mathrm{~cm}$, then the average density of fuel elements will be $.0001 \mathrm{gm} / \mathrm{cm}^{3}$.

Such a low average density means that the size of the reactor core will be fairly large unless one uses a fissile material, e.g. Am ${ }^{242 m}$, with an especially large fission crosssection. In Table I we compare the critical masses of some fissile isotopes, assuming the fissile material uniformly fills a cylindrical core with a diameter of 1 meter and a length of 5 meters, surrounded by 3 meters of heavy water.

Table I. Critical Masses

$\begin{array}{lr}\mathrm{Am}^{242 \mathrm{~m}} & 0.5 \mathrm{~kg} \\ \mathrm{Cm}^{245} & 1.1 \mathrm{~kg} \\ \mathrm{Pu}^{239} & 5.6 \mathrm{~kg} \\ \mathrm{U}^{235} & 11 \mathrm{~kg}\end{array}$

Although the critical mass will depend somewhat on the exact geometry and choice of moderator/reflector this table should suffice for estimating the size of a reactor core for which the average density of fissile material is below the maximum allowable $\sim 10^{-4} \mathrm{gm} / \mathrm{cm}^{3}$. It should be noted that only for $\mathrm{Am}^{212 \mathrm{~m}}$ is the average fuel density for the particular case of a $1 \mathrm{~m}$ diameter by 5 meter long core low enough. More practical fuels such as $\mathrm{Pu}^{239}$ or $\mathrm{U}^{233}$ would evidently require a core which is roughly a few times larger. Monte Carlo neutronic calculations ${ }^{2}$ suggest that a $4 \mathrm{~m}$ diameter by $10 \mathrm{~m}$ long core would allow average densities of $\mathrm{Pu}^{239}$ below $.0001 \mathrm{gm} / \mathrm{cm}^{3}$. Of course, one of the transverse 
dimensions of the reactor core must be small enough to allow efficient extraction of the fission fragments using magnetic fields. In practice this means it will probably. be necessary to use a reactor core with a rectangular crosssection, one side of which is no more than about $1 \mathrm{~m}$ across. The other dimension of the rectangle will be dictated by the need to limit the time that the fuel spends inside the reactor core (see next Section). However, a prototype reactor operating at a power below $100 \mathrm{MW}$ could be configured as a slab whose thickness is on the order of $1 \mathrm{~m}$, and height and width are on the order of $10 \mathrm{~m}$.

Because of the low average fuel density in the reactor core a fission fragment rocket will necessarily operate as a thermal reactor. Furthermore Monte Carlo neutronic calculations indicate that the temperature coefficient of reactivity will be safely negative.

\section{THERMALMANAGMENT}

The power that can be generated by a fission fragment rocket will be limited by the rate at which waste heat can be carried off. The amount of waste heat generated will be mainly determined by the efficiency of extracting and utilizing the fission fragment kinetic energy. In a typical fission reaction about $85 \%$ of the energy released appears in the form of fission fragment kinetic energy. The remaining $15 \%$ of the energy is carried off by neutrons, gamma rays, beta rays, and neutrinos. Assuming that $50 \%$ of the fission fragment kinetic energy is available for direct conversion to electricity, then the energy produced by a $\mathrm{Pu}^{239}$ fueled fission fragment rocket will be partitioned approximately as shown in Table II (cf. Ref. 3):

\section{Table II. Energy Balance}

$\begin{array}{lr}\text { Fission Fragment Exhaust } & 42 \% \\ \text { Deposited in Fuel Fibers } & 44 \% \\ \text { Deposited in Reflector } & 7 \% \\ \text { Escape From Reactor } & 7 \%\end{array}$

Obviously the most serious thermal management problem is how to keep the fuel fibers from melting. Fortunately the idea of fabricating the fuel elements as thin carbon fibers coated with fissile fuel of fers a unique solution to this problem. Because the fuel fibers have a very small diameter, the fuel has a very large surface area, and so the fuel fibers can cool themselves radiatively. For example, if we assume that the fuel elements consist of $2 \mu \mathrm{m}$ diameter carbon fibers with a $0.5 \mu \mathrm{m}$ thick coating of plutonium then one metric ton of fissile fuel will have an area of $10^{5} \mathrm{~m}^{2}$. At a temperature of $1100^{\circ} \mathrm{K}$ this is sufficient area to radiate away $10^{10} \mathrm{~W}$ ! Thus the fuel elements can radiatively cool themselves at temperatures well below their melting point. Of course, only about 10 kilograms of fuel are inside the reactor core at any given time, so that one would have to rapidly circulate the fuel elements through the reactor core if the reactor power exceeds about $100 \mathrm{MW}$ th. One way to rapidly circulate the fuel elements through the reactor core is schematically shown in Fig. 1. In this scheme the fuel fibers are attached to a rotating shaft and kept straight by centrifugal forces. Calculations of fuel temperatures ${ }^{3}$ indicate that with angular velocities on the order of 50 radians/sec and fiber lengths $\leqslant 1400^{\circ} \mathrm{K}$. If one wanted to use $\mathrm{Pu}^{239}$ as the fuel it would probably be necessary to use an alloy of plutonium because pure plutonium has an anomalously low melting point.

In the case of $\mathrm{Pu}^{299}$ approximately $7 \%$ of the energy produced will be deposited in the reflector/moderator. For a $1 \mathrm{GW}_{\mathrm{th}}$ power plant this means that $70 \mathrm{MW}_{\text {th }}$ must be continuously removed from the reflector/moderator. If the reactor core is $1 \mathrm{~m}$ in diameter and $20 \mathrm{~m}$ long and surrounded by $0.5 \mathrm{~m}$ of graphite this could be accomplished ${ }^{3}$ by transporting the heat to the outer surface of the graphite via ordinary thermal conduction and then using fins to radiate away the heat. For cogeneration purposes one might want to supplant this radiative cooling with water cooling, but it is an important safety feature that the cooling could be carried out entirely passively. In any case a $1 \mathrm{GW}_{b}$ fission fragment rocket power plant would not require the giant cooling towers required by present day nuclear power plants.

\section{FISSION FRAGMENT EXTRACTION}

In order to take advantage of the possibility of directly converting the fission fragment kinetic energy into electricity one must arrange for the fission fragments to escape from the reactor core as they are produced. In our present conception of the fission fragment rocket the fission fragments are guided out of the reactor core using magnetic fields. In particular one might hope to devise a magnetic field such that as the fission fragments are emitted from the layers of fuel fibers their paths are bent so that the fission fragments avoid further encounters with a fuel layer before exiting the reactor core via a slit in the reflector. The design of a magnetic field to accomplish this task is complicated by the requirement that the electric currents used to generate the magnetic field must flow in conductors external is the reactor core. We do not know how to approach the problem of finding an optimal arrangentent of external conductors in a systematic way. Most of our efforts to date have focussed on an arrangement of currents like that shown in Fig. 2. In this arrangement six vertical currents, IV and IVA, create a magnetic field that is uniform in the vertical direction but divergent in any horizontal plane. This divergence in the radial direction creates a $\mu \cdot \nabla \mathrm{B}$ outward force on the fission fragments, allowing them to be extracted via a series of horizontal slits in the outer reflector wall. As shown in. Fig. 2 alternating horizontal currents $I_{H}$ have been added to guide the fission fragments into the slits.

The arrangement of currents shown in Fig. 2 will produce two oppositely directed fans of fission fragments. In Figs. 3 we show some typical fission fragment trajectories for fission fragments emitted omnidirectionally from the origin. The currents shown in Fig. 2 were assumed to have values $I_{v}=8 \mathrm{MA}, I_{V A}=1.4 \mathrm{MA}$, and $I_{H}=$ $2 \mathrm{MA}$. These currents will give rise to magnetic fields with strengths on the order of 10 Tesla. As is evident from Fig. 3a one would want horizontal slits approximately $15 \mathrm{~cm}$ wide and spaced approximately $40 \mathrm{~cm}$ apart in order to get reasonable extraction efficiencies. Comparison of the number of $x=0$ and $y=0$ plane crossings suggests that the fuel layers should be oriented parallel to the $x-z$ plane; i.e. perpendicular to the horizontal slits. If each fuel laver is 1 


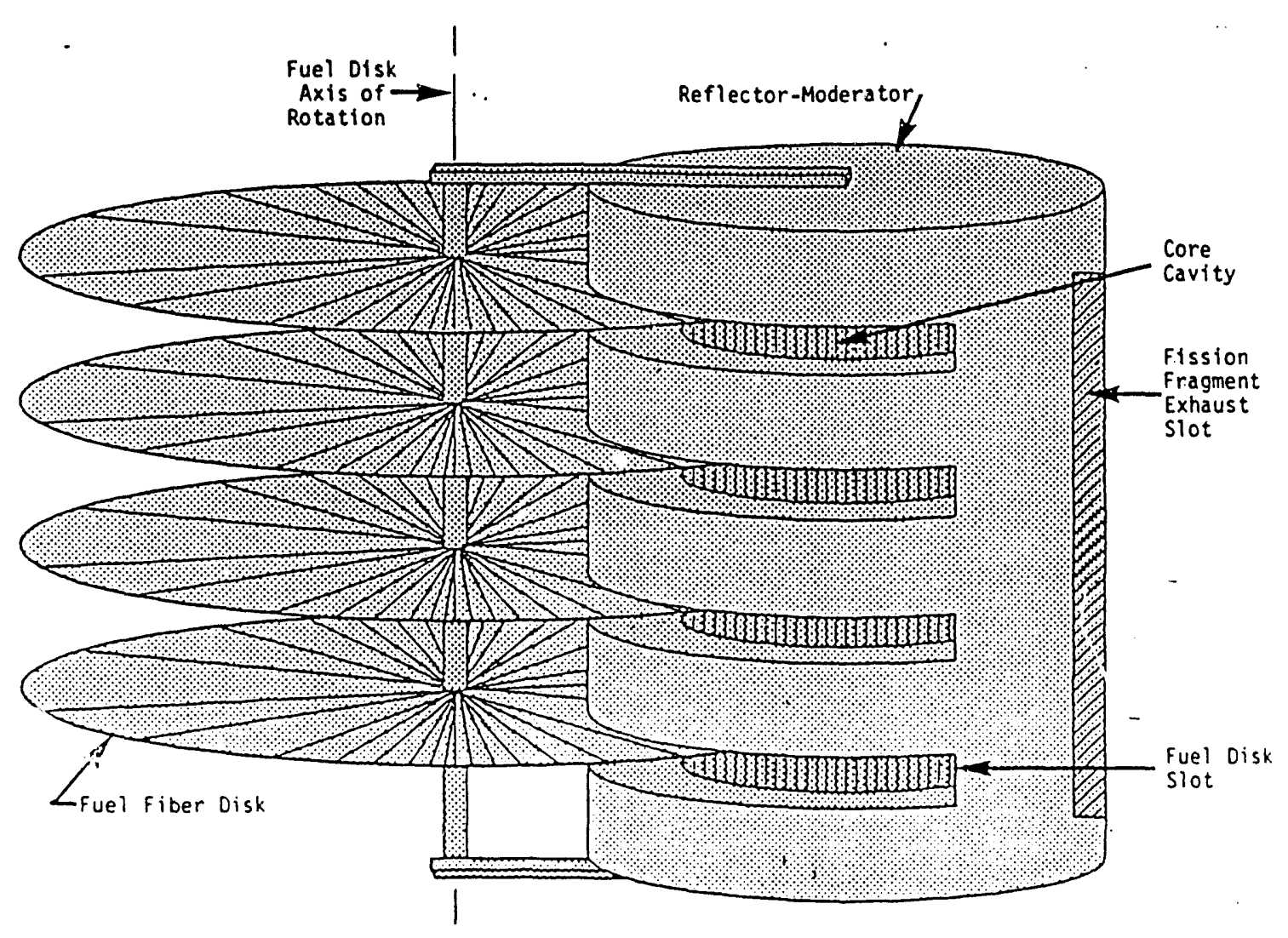

Fig. 1 Schematic of fission fragment rocket with rotating fuel fibers.

and $20 \mathrm{~cm}$ apart, then the trajectory calculations shown in Fig. $3 \mathrm{~b}$ suggest that approximately $25 \%$ of the fission fragments could be extracted. It is our hope that with further work the extraction efficiency can be increased to $50 \%$.

The "exhaust" of a fission fragment rocket utilizing an arrangement of currents like that shown in Fig. 2 would consist of oppositely directed sprays of ionized particles with an energy somewhat less than 1 million electron volts per AMU. The kinetic energy of these particles could be converted into high voltage electricity using electrostatic converters similar to those that have been designed for magnetic mirror machines. 5 If one assumes that $50 \%$ of the fission fragments can be extracted from the reactor core, then approximately $40 \%$ of the total energy produced in the fission fragment rocket could be directly converted into electricity. Assuming that $30-40 \%$ of the remaining energy could be converted into electricity through thermal cycles, then it may be possible to achieve overall efficiencies for the production of electricity approaching $60 \%$.

\section{CONCLUSION}

Preliminary investigations of the fission fragment rocket concept suggest that this concept offers some interesting possibilities for electric power production. In particular, continuous extraction of the fission fragments from the reactor core holds out the promise that approximately $40 \%$ of the energy generated by a fission fragment rocket could be directly converted to high voltage electricity. When one adds in the useful energy that could be extracted from the waste heat one is talking about a power

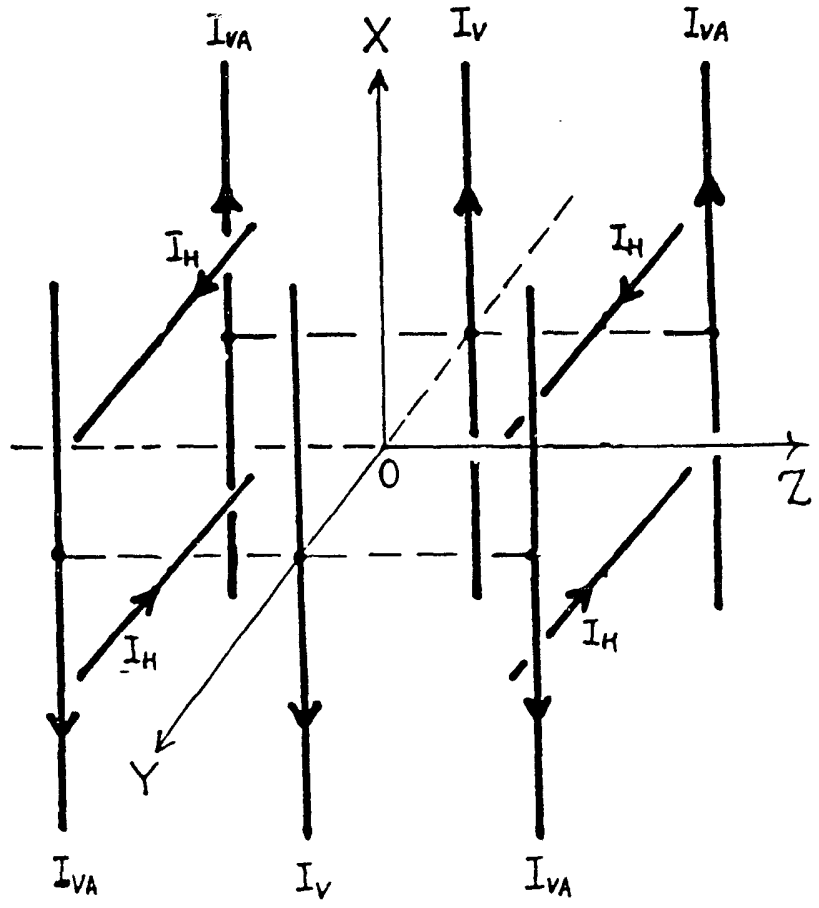

Fig. 2 Trial arrangement of currents for generating the magnetic field 


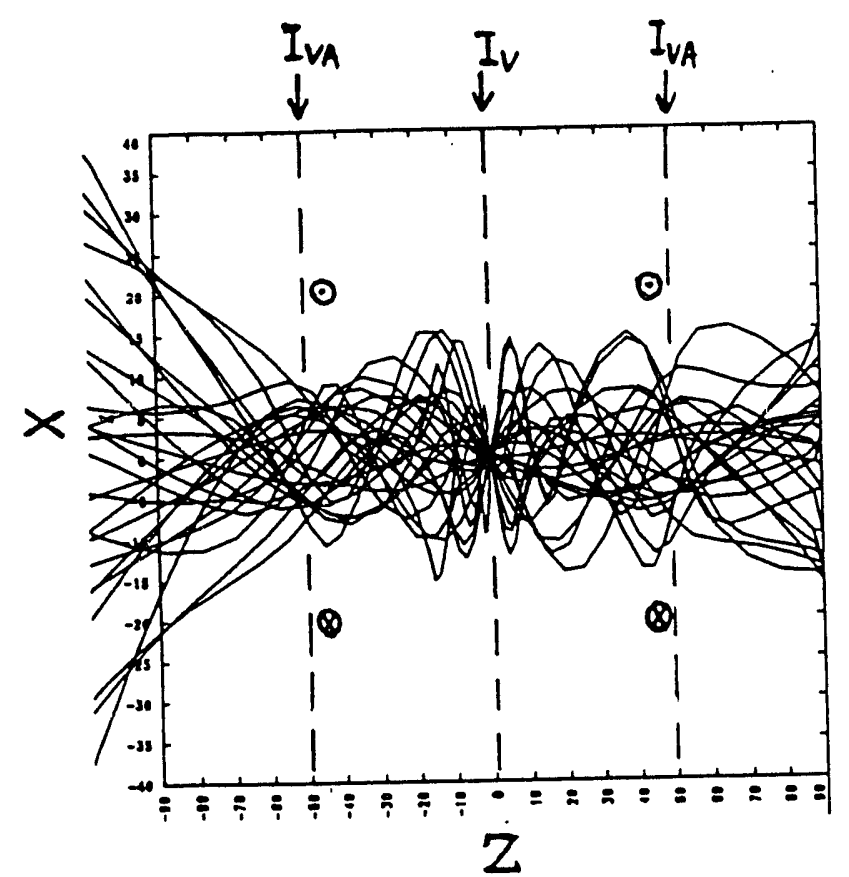

Fig. 3a Projection of fission fragment trajectories onto the $y=0$ plane.

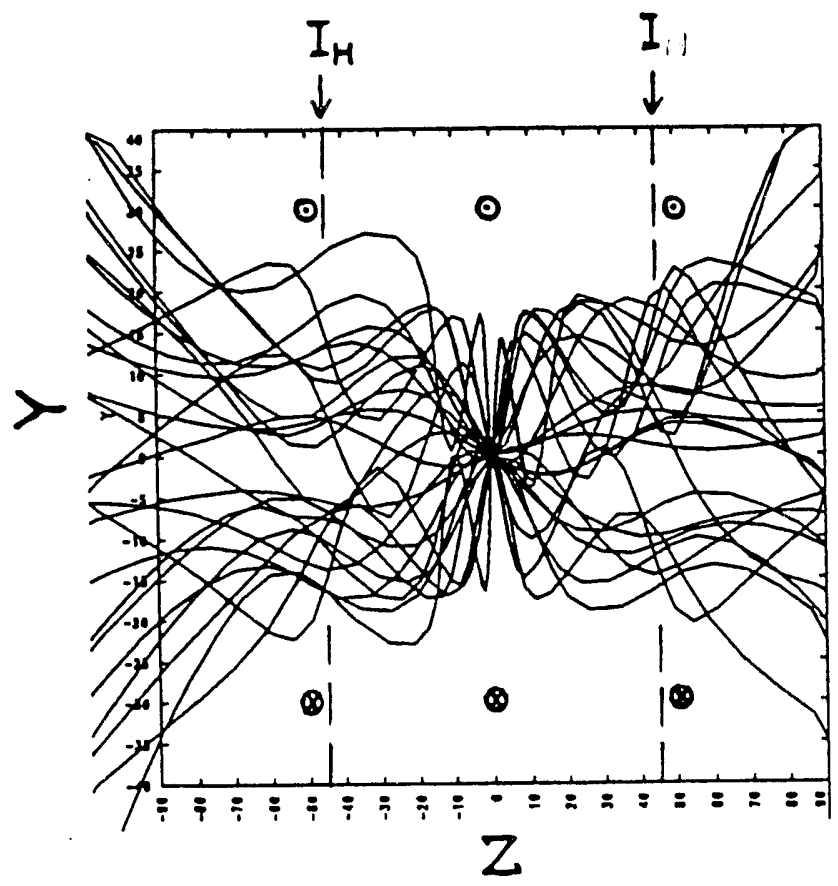

Fig. 3b Projection of fission fragment trajectories onto the $x=0$ plane. plant that is twice as efficient as the most efficient conventional nuclear reactors. Furthermore, continuous removal of the fission fragments from the reactor core offers some ancillary advantages.

Perhaps the most obvious ancillary advantage of continuous extraction of fission fragments from a reactor core is that the buildup of an inventory of fission products inside the reactor would be slowed. The sudden release into the atmosphere of a large inventory of fission products was what made the consequences of the Chernobyl accident so serious and widespread. Apart from the desire to increase electric efficiency consideration of reactor safety provides a strong motivation for extracting as many fission fragments from the reactor core as possible.

Another potential advantage of continuous removal of fission fragments from the reactor core is that this could help solve the radioactive waste disposal problem. Indeed continuous removal and separation of the most dangerous fission products, e.g. $\mathrm{Cs}^{135}$ and $\mathrm{Tc}^{99}$, might greatly simplify the problem of finding a practical method for permanently storing these nuclides. In addition continuous removal of the fission products may facilitate nuclear transmutation of the most dangerous nuclides. In the case of $\mathrm{Cs}^{135}$ continuous removal would permit transmutation of the $\mathrm{Cs}^{135}$ without isotopic separation of $\mathrm{Cs}^{135}$ from $\mathrm{Cs}^{133}$. $^{6}$

\section{ACKNOWLEDGEMENTS}

The authors are grateful to Bruce Schnitzler for his help in preparing the poster paper and to John Nuckolls for his support and encouragement. Work performed under the auspices of the U.S. Department of Energy by Lawrence Livermore National Laboratory under contract W-7405-Eng48.

\section{REEERENCES}

\section{G. CHAPLINE, "Fission Fragment Rocket Concept," Nuclear Instruments and Methods in Physics Besearch A271, 1988, 207-208.}

2. G. F. Chapline, W. H. HOWARD, and B. G. SCHNITZLER, "Fission Fragment Rockets - A New Frontier," in 50 Years with Nuclear Fission, ed. J. Behreus and A. Carlson, ANS, 1989, 601-605.

3. B. G. SCHNITZLER, J. L. JONES, and G. F. CHAPLINE, "Fission. Fragment Rocket Scientific Feasibility Assessment," Idaho National Engineering Laboratory Report EGG-NERD-8585, June 1989.

4. G. H. MILEY, "Direct Conversion of Nuclear Radiation Energy," ANS, 1970.

5. R. W. MOIR and J. D. LEE, "Criteria for Design of an Adiabatic Expander for a Direct Energy Converter," Lawrence Livermore Laboratory Report TID-4500, April 1973.

6. C. Bowman, this proceedings. 

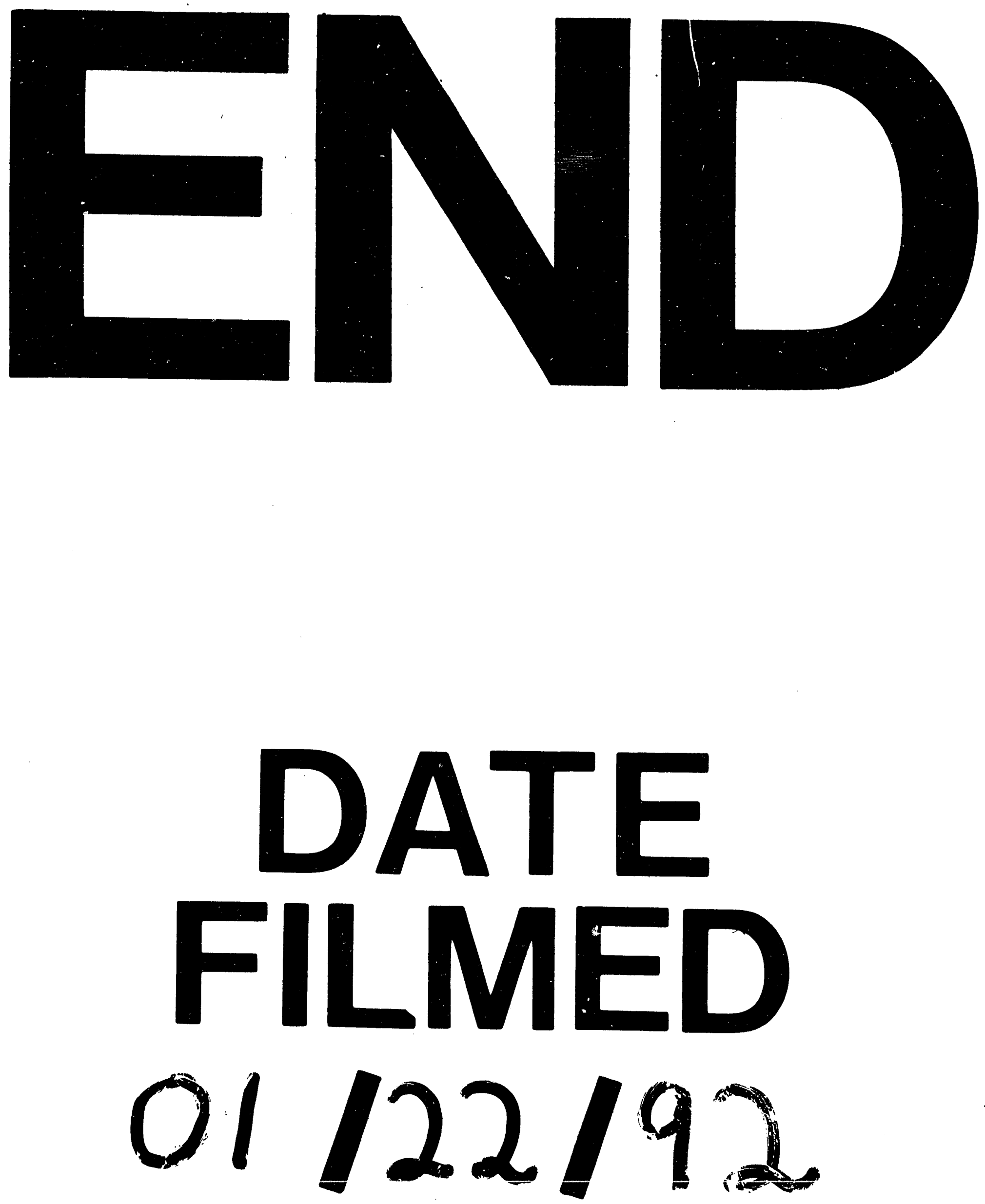
